\title{
INTERCULTURALIDADE E ATENÇÃO DIFERENCIADA: APONTAMENTOS PARA UM DEBATE SOBRE A POLÍTICA DE SAÚDE INDÍGENA BRASILEIRA EM TEMPOS DE CRISE SANITÁRIA ${ }^{1}$
}

CRISTINA DIAS DA SILVA ${ }^{2}$

UFJF, BRASIL

https://orcid.org/0000-0001-8360-5272

\begin{abstract}
RESUMO: Este artigo busca refletir sobre elementos históricos relacionados à interculturalidade no campo da saúde pública com vistas a analisar a atual política nacional para a saúde dos povos indigenas no Brasil. A hipótese é de que a interculturalidade na saúde poderia ser pensada, sob certos aspectos, através da interface com a educação em saúde, outrora chamada de pedagogias sanitárias, e que agenciaram a noção de diálogo intercultural durante a maior parte do século XX. No Brasil, um dos reflexos mais notáveis deste processo histórico culminou com a Política Nacional de Atenção à Saúde Indígena em 2002, seguindo preceitos de interculturalidade sob o rótulo da "atenção diferenciada". Assim, a proposta é analisar algumas especificidades históricas deste campo de produção de politicas de saúde buscando, a um só tempo, pensar a interculturalidade como resultado de processos históricos de médio e longo prazo no campo da saúde e constituir suas especificidades no contexto brasileiro em meio à crise político-sanitária da covid-19.
\end{abstract}

PALAVRAS-CHAVE: interculturalidade, políticas de saúde pública, saúde indígena, Brasil.

ABSTRACT: This article seeks to reflect on historical elements related to interculturality in the field of public health with a view to analyzing the current national policy for the health of indigenous peoples in Brazil. The hypothesis is that interculturality in health could be thought, under certain aspects, through the interface with health education, formerly called health pedagogies, and which guided the notion of intercultural dialogue during most of the 20th century. In Brazil, one of the most notable reflections of this historical process culminated in the National Policy for Indigenous Health Care in 2002, following the precepts of interculturality under the label of "differentiated care". Thus, the proposal is to analyze some historical specificities of this field of health policy production, seeking, at the same time, to think of interculturality as a result of medium and long-term historical processes in the field of health and to constitute its specificities in the Brazilian context in the to the political-sanitary crisis of covid19.

KEYWORDS: interculturality, public health policies, indigenous health, Brazil.

\footnotetext{
${ }^{1}$ Este texto é dedicado à memória do Cacique Vicente Saw Munduruku, falecido em $1^{\circ}$ de junho de 2020 em decorrência da Covid-19, estado do Pará, Brasil.

2 Professora Associada de Antropologia no Departamento de Ciências Sociais e no Programa de PósGraduação em Ciências Sociais da Universidade Federal de Juiz de Fora. Contato: cristina.dias@ufjf.br SILVA, Cristina Dias da. Interculturalidade e atenção diferenciada: apontamentos para um debate sobre a política de saúde indígena brasileira em tempos de crise sanitária. Espaço Ameríndio, Porto Alegre, v. 15, n. 2, p. 146-163, mai./ago. 2021.
} 


\section{Introdução}

Este texto tem como objetivo explorar alguns aspectos do que poderíamos chamar de interculturalidade na saúde indígena brasileira. Para tanto, e no sentido de fornecer subsídios a um debate mais amplo, o artigo inicia com uma digressão histórica ao período da reforma sanitária elegendo um eixo de reflexão (as pedagogias sanitárias e campanhas de educação em saúde) junto a outros países latinoamericanos, a partir do qual estabelece um recorte para compreender pontos de tensão atuais no campo das políticas de saúde indígena, em especial, os modos de percepção da noção de cultura, assim como elementos históricos que dão sentido às formas peculiares do fenômeno da interculturalidade no Brasil, com destaque para o uso que tem sido dado à noção de atenção diferenciada no campo da saúde indígena brasileira, conforme discutem Teixeira (2017) e Langdon e Diehl (2007) ${ }^{3}$.

Um dos primeiros aspectos a se chamar atenção seria, portanto, as iniciativas em torno da chamada interculturalidade, traduzida no contexto brasileiro para expressões como "atenção diferenciada" ou, ainda, "especificidades culturais", para citar as duas mais comuns nos textos oficiais das políticas públicas para saúde dos povos originários, como é o caso da Política Nacional de Atenção à Saúde dos Povos Indígenas - PNASPI (BRASIL, 2002), como também entre seus especialistas e agentes governamentais, conforme apontam vários estudos recentes sobre o cotidiano da assistência em saúde aos povos indígenas (DIAS DA SILVA, 2010; NOVO, 2010; PONTES, REGO E GARNELO, 2015; DIEHL, LANGDON E DIAS-SCOPEL, 2012; FERREIRA, 2010). Sabemos que o projeto de reconhecimento da diversidade cultural no plano do atendimento à saúde é uma premissa derivada do texto constitucional de 1988, e que se concretizou na publicação da PNASPI em 2002. Entretanto, a construção desta tecnologia burocrática e informacional não se traduziu automaticamente no reconhecimento de uma dimensão intercultural. As etnografias citadas nos apontam para uma produção frequente de outros sentidos para a premissa do atendimento ou atenção diferenciada na saúde indígena brasileira, em que pese sua importância ao debate antropológico e à própria concepção derivada do texto da PNASPI. Assim, cabe evidenciar estes contextos nos quais a noção de cultura é usada de modo reificado, justificando violências simbólicas e políticas em razão da própria diversidade cultural (TEIXEIRA E SILVA, 2019). Esses

\footnotetext{
${ }^{3}$ No caso do artigo de Langdon e Diehl, destaca-se uma leitura interessante do significado do termo Atenção diferenciada entre os próprios agentes indígenas de saúde no contexto do Sul do país, exaltando a complexidade da noção: "As respostas dos AISs quando perguntamos nos grupos focais especificamente sobre o significado da atenção diferenciada, indicaram que para eles o conceito refere-se ao aspecto de acesso universal e igualdade na qualidade de serviços. Alguns afirmaram que "O índio não tem que esperar em fila mais", justificando um status especial diante dos serviços de saúde. Ao perguntarmos especialmente sobre os saberes tradicionais de saúde, a maior parte dos AISs afirmou ter pouco conhecimento de práticas indígenas e referiu os mais velhos, frequentemente as mulheres, como detentoras desses "segredos". Reclamaram ainda que elas atendem os doentes, mas não revelam seus segredos." (2007, p.26) (grifos das autoras). Já a referência ao texto de Carla Teixeira engloba também certa perspectiva em torno dos manejos da diversidade na saúde indígena brasileira ao acionar a análise de tal categoria nos contextos das conferências nacionais de saúde indígena.

SILVA, Cristina Dias da. Interculturalidade e atenção diferenciada: apontamentos para um debate sobre a política de saúde indígena brasileira em tempos de crise sanitária. Espaço Ameríndio, Porto Alegre, v. 15, n. 2, p. 146-163, mai./ago. 2021.
} 
"desentendimentos" ou "mal-entendidos" podem ser compreendidos como um dado importante para a reflexão sobre certa ambiguidade em torno dos sentidos atribuídos à interculturalidade enquanto atenção diferenciada na saúde indígena. Seguindo a proposta deste artigo, apresento a seguir uma digressão sobre aspectos da história da saúde pública em outros países latino-americanos e no Brasil que apontam para diferenças e semelhanças na construção de um campo político e educacional em torno da saúde pública, com ressonâncias possíveis dentro do campo da saúde indígena, como argumentarei na sequência.

\title{
Pedagogias sanitárias na América Latina: breve digressão
}

Sobre a interculturalidade como projeto educacional nos países latino-americanos, Souza Lima e Carvalho (2018) enfatizam que, mais do que prescrever, é importante dar a conhecer os sentidos que o intercultural assumiu historicamente no campo da educação:

\begin{abstract}
suspender as certezas e enfatizar os contextos de seu uso pode ser uma boa via de acesso para entender essas variações e nos fazer defrontar as histórias das diferentes maneiras como os povos indígenas foram tratados por governos nacionais ao longo do século $\mathrm{XX}$, das quais a generalização da interculturalidade como projeto de futuro (educacional) é capítulo muito recente. E para podermos conhecer, mais que prescrever o que seja a interculturalidade, não faremos nesta breve apresentação qualquer esforço de definição de seus significados. (Souza Lima e Carvalho, 2018, p.9) (grifos meus)
\end{abstract}

Tratar-se-ia do reconhecimento de que é necessário refletir detidamente sobre o contexto histórico que permitiu a formação e uso de certos conceitos que, uma vez popularizados no senso acadêmico e no interior das políticas públicas, passam a integrar nosso campo semântico. Embora o termo interculturalidade seja recente na saúde, a ideia de que é preciso equacionar diferenças sociais e culturais não o é. Ela remete às primeiras décadas do século $X X$, quando, na efervescência política da reforma sanitária, uma série de iniciativas foi levada a cabo por agentes governamentais, entre agentes públicos, cientistas brasileiros (Oswaldo Cruz, Vital Brazil, Arthur Neiva, Belisário Penna) e organismos internacionais (Fundação Rockefeller, Organização de saúde da Liga das Nações [atual OMS]) para reduzir a incidência de doenças epidêmicas e endêmicas nas cidades e nas áreas rurais, como era o caso da febre amarela, ancilostomíase, tifo, varíola, sífilis, entre outras.

A percepção de que a saúde pública precisava entrar na agenda política da Nova República foi crucial e, junto dela, interpretações do Brasil, assim como de muitos outros países latino-americanos, foram agenciadas pelas suas respectivas elites intelectuais e científicas em 
publicações, discursos e políticas públicas. Em uma das coletâneas de referência para o tema da construção sócio-histórica da saúde pública na América Latina, organizada por Gilberto Hochman e Diego Armus (2004), notamos que a maioria dos autores enfatiza o papel da Fundação Rockefeller na centralização das ações em saúde, bem como a ascensão da classe médica na América Latina como evento político que impulsionou o debate sobre os nacionalismos através de pedagogias sanitárias. Destacam, ainda, o desenvolvimento da saúde pública como projeto político de modernização, que passava pela superação de obstáculos que iam da infraestrutura, esgotamento sanitário, construção de latrinas até as ações educativas e que visavam modificar comportamentos ao mesmo tem em que disseminavam preconceitos e estigmas variados em relação aos povos nativos, com o apoio de médicos, professores e funcionários públicos da administração federal.

O uso de estratégias de convencimento da população, como a educação sanitária e suas campanhas educativas em saúde, começa a ser pensada e desenvolvida em uma série de países latino-americanos, tais como Colômbia, México, Costa Rica, Peru, Argentina, Brasil, entre outros (HOCHMAN E ARMUS, 2004). Cueto (2004), por exemplo, discute como no Peru das décadas de 1920 e 1930 teve início uma iniciativa pioneira de brigada sanitária, desenvolvida pelo médico Manuel Nuñez que: "respeitou valores comunitários e, paralelamente, usou os povos indígenas para ampliar a vacinação contra varíola e promover uma campanha contra o tifo epidêmico." (CUETO, 2004, p.297). O autor destaca o trabalho artesanal do médico pelos interiores peruanos, angariando voluntários entre os povos indígenas, bem como sua capacidade de articular saberes médicos e indígenas para produzir melhores resultados na saúde pública. Temos, de algum modo, as primeiras bases do que viria a ser a noção de interculturalidade em saúde neste singular caso peruano, podendo visualizá-lo como um processo histórico em várias etapas, com peculiaridades regionais em termos de figuras de destaque, como o próprio Manuel Nuñez, que articularia não apenas saberes distintos, mas que mobilizaria populações locais em torno de problemas de saúde pública sem recorrer aos argumentos eugênicos em voga na época. O indigenismo, um importante movimento político e cultural peruano que estava em evidência nos anos de 1930, se tornou elemento central das campanhas educativas promovidas pela brigada sanitária de Nuñez. Além disso, a brigada contava com mulheres em posição de liderança, indígenas que haviam servido ao exército, além de curandeiros e herbanários (2004, p.311). Nesse contexto muito bem descrito pelo autor, percebemos que havia disputas significativas sobre a noção de cultura, culturas indígenas e cultura peruana agenciando os debates públicos. Bem como, havia críticas à ideia de que as comunidades tradicionais constituíam obstáculos à produção de uma saúde coletiva por seus hábitos. Essa disputa, portanto, localizada no seio dos atuais debates sobre interculturalidade, tem um histórico bastante longo, que retrocede a contextos políticos nacionais variados. 
No caso da Colômbia, Noguera (2004, p.111) mostra o quanto as campanhas de conscientização da população sobre os perigos do uso de bebidas alcóolicas, que contavam com o empenho dos médicos locais, estavam todas direcionadas à Chicha, bebida de milho tradicional indígena. Em vez de Chicha, o governo, através de campanhas de saúde pública, incentivava o consumo de cerveja, uma bebida considerada fortificante e higiênica pelos médicos. A campanha, que começou nos anos vinte do século XX e durou quase cinquenta anos, ficou conhecida como luta antialcoólica e disparou o consumo de cerveja por todo o território colombiano, beneficiando negociantes estrangeiros que conformavam a elite local. Tal empresa logrou ter sucesso após décadas de discriminação em torno da bebida tradicional indígena. Mesmo em face das contradições inerentes ao discurso da luta antialcoólica, a população trabalhadora continuava sendo culpada por seus hábitos, por beber, por não ter saúde, por não ser produtiva. E as culturas indígenas estiveram sempre no centro dos discursos médico-políticos. Aqui, a negociação com os pontos de vista indígenas, embora diferente do caso peruano, tem algo em comum: os problemas de infraestrutura são ignorados ou, até mesmo, usados como fator tributário de aspectos culturais. Vemos no caso colombiano um conjunto de violências simbólicas significativas que não esmoreceram com o passar de mais de um século, dentre as quais podemos destacar: a correlação entre povo doente e pátria subdesenvolvida, a culpabilização dos povos originários por seus hábitos ditos não saudáveis e a percepção de que a saúde pública tinha um caráter de higienismo social acolhido pelos agentes governamentais à época. Assim, é importante destacar que a noção de interculturalidade surge em um cenário histórico no qual sempre foi preciso lutar para que as diferenças culturais não fossem absorvidas por um campo semântico pedagógico que reproduz violências simbólicas e políticas.

Outro exemplo expressivo do reconhecimento de lógicas e conhecimentos comunitários para a produção de políticas públicas de saúde diz respeito à atuação da Fundação Rockefeller na América Latina neste período. A Fundação foi responsável pela criação de numerosas inciativas em saúde pública, por meio de arranjos políticogovernamentais que incluíam não apenas a transferência de conhecimentos (tecnologia burocrática), criação de laboratórios, mas, também, a autoridade para a fiscalização de atividades científicas e da própria população local (LÖWI, 1999).

A Fundação Rockefeller teve atuação notável na primeira metade do século XX. Segundo dados de Faria (1995), ela atuou não apenas na América Latina (Brasil, Colômbia, Chile, Paraguai, Peru, Uruguai, Venezuela, Costa Rica, Cuba, Equador, Guatemala, Haiti, Nicarágua, El Salvador, Jamaica, Trinidad e Tobago, Granada), mas também na Ásia (Sri Lanka, Índia, Malásia, Coreia, Tailândia, China e Japão), Oriente Médio (Iraque, Turquia, Israel e Líbano) e Europa (Portugal, Albânia, Irlanda, Escócia, Espanha e Inglaterra). Embora caiba uma série de ressalvas sobre a forma de atuação em cada um desses continentes e na época histórica 
específica em que ocorreram essas intervenções, salta aos olhos a magnitude da empreitada da Fundação, uma organização nãogovernamental que levou quatro anos para conseguir do congresso estadunidense licença para atuar internacionalmente (Faria, 1995, p. 1 14). Vale lembrar que a Fundação Rockfeller investiu algo em torno de treze milhões de dólares entre 1914 e 1949 na criação e desenvolvimento de programas sanitários na América Latina (Faria, 1995, p.118).

Propondo uma chave de leitura distinta para a atuação da fundação, Palmer (2004) considera que, ao menos no caso Costa-riquenho, houve mesmo um estímulo interessante ao nacionalismo através de uma íntima relação de cooperação profissional entre agentes da Fundação Rockefeller e médicos locais, que ajudou a produzir soluções competentes para controlar os surtos de ancilostomíase (Palmer, 2004, p.237-8). O autor procura destacar uma visão compreensiva da atuação da entidade, expurgando desconfianças sistemáticas em relação a um imperialismo cultural reducionista. Seus dados mostram o quanto a comunidade científica costa-riquenha, por pequena que fosse, estava plenamente engajada e consciente da atuação da Fundação e que tal empreendimento abriu espaço para importantes debates nacionais, que beneficiaram a Costa Rica, sobretudo, pela disposição dos agentes estadunidenses em negociar pontos de vista locais. Löwi (1999), numa visão menos condescendente com a atuação da Fundação Rockefeller, aponta interesses políticos mais específicos em consonância com a competência de seus agentes em se adaptar às questões culturais locais. Para a autora, a entidade tendia a ignorar aspectos históricos fundantes das desigualdades sociais e focar em elementos que pudessem produzir uma eficácia visível de sua atuação, como as tentativas incessantes de eliminar completamente o mosquito Aedes aegypti da América Latina entre as décadas de 1920 e 1960. Assim, a ênfase na educação em saúde não significava um investimento no combate às desigualdades sociais, mas um investimento específico em munir a população de conhecimentos biomédicos necessários sobre o ciclo de vida e hábitos de mosquitos e outros vetores, além da observação e modificação de seus próprios hábitos que produzissem resultados epidemiológicos negativos, o que se poderia chamar de pedagogia sanitária, e que nem sempre era apenas uma estratégia educativa:

A familiaridade com o estilo de vida, a cultura, as crenças e os padrões de comportamento das populações locais não era vista como precondição para um trabalho eficiente contra os mosquitos. Bastava saber como elas deviam comportar-se e então obter as prerrogativas legais adequadas para impor-Ihes tal comportamento. (Löwi, 1999, p.672)

Esse debate nos importa porque, ao se falar de aspectos históricos da interculturalidade em saúde, percebemos que, para além do dissenso sobre a atuação de agentes internacionais nos países latino-americanos e suas consequências políticas, os autores que escrevem sobre as 
campanhas sanitárias entre as décadas de 1920 e 1930 abordam justamente a articulação de saberes locais e científicos. Muito embora fossem reconhecidas que as precárias condições de vida e de trabalho das populações rurais e urbanas seriam impedimentos claros a um nível de saúde coletiva satisfatório, a população periférica se tornou, já nessa época, um obstáculo para a produção dos resultados, devendo ser, em certo aspecto, combatida, em vez de alfabetizada, por exemplo. Por tal razão, Löwi explicita os desentendimentos entre os intelectuais brasileiros e norte-americanos quanto ao modo de entender que a crise sanitária deveria voltar-se a uma consideração específica sobre os interiores brasileiros, algo que os agentes da Rockefeller não estavam dispostos a concordar:

A teoria do foco-chave e suas consequências, sobretudo a ênfase na 'limpeza' e modernização das cidades, condicionavam a percepção que os funcionários da Rockefeller tinham do interior do Brasil. Esta hinterlândia era descrita quase sempre como desolada e miserável, tendo-se vislumbres ocasionais de paraíso terreno e das potencialidades da terra. Contudo, a irremediável situação do interior não importava muito para o futuro da campanha contra a febre amarela, pois se esperava que a salvação viesse exclusivamente das atividades antilarvárias realizadas nas cidades. (1999, p.652)

Löwi destaca, ainda, o lema da fundação, que considerava a saúde precária como causa da pobreza, e não o contrário. É possível perceber, através do lema que movia seus agentes, que a interferência no modo de vida da população era baseada numa percepção de que a população periférica, sobretudo dos interiores e latino-americana, não tinha salvação (perspectiva eugênica), e as estratégias de controle se davam, sobretudo, através da negociação com as elites locais em torno de legislação favorável a seus modelos de eficiência. A pobreza era um obstáculo para a produção de saúde, mas não era um elemento a ser combatido em suas raízes, isto é, o foco não era a desigualdade social, mas o manejo político das diferenças culturais (TEIXEIRA, 2012; DIAS DA SILVA, 2010). Assim, a política de controle das doenças através da educação sanitária e da exterminação de vetores, mosquitos e focos de transmissão não visava reduzir as desigualdades, mas modificar comportamentos, hábitos e estilos de vida que estavam esteticamente comprometidos com a ideia de tradicional e "atrasado".

No trabalho de Weindling (2006) sobre a Organização de Saúde da Liga da Nações Unidas (1924-1945), predecessora da Organização Mundial de Saúde (OMS), fica claro que muitos dos seus objetivos, ao construir uma consciência sobre a necessidade de internacionalizar o debate sobre saúde pública, enfrentavam obstáculos produzidos pelos interesses conflitantes dos EUA e da Europa sobre o território latinoamericano. E, o que surgiu inicialmente como medidas de produção de uma saúde mundial e de prevenção às guerras, tornou-se, com o passar 
do tempo, um intrincado arranjo político dos interesses pela condução dos processos de modernização nos chamados países subdesenvolvidos. A Liga das Nações teve papel fundamental em correlacionar dados socioeconômicos a dados médicos, mas à medida que tais vínculos se tornavam mais claros, interesses políticos reduziam o alcance das conclusões a que os especialistas chegavam e ignoravam teses "perigosas" sobre a pobreza e a desigualdade social, reduzindo-as, muitas vezes, a obstáculos sobre os quais ninguém queria assumir responsabilidade efetiva, sobretudo no caso latino-americano:

O modelo de saúde pública da Organização de Saúde da Liga das Nações não levou em conta questões como controle da natalidade e o perigoso potencial das medidas sanitárias para promover a segregação racial e o genocídio, como na imposição de guetos e no uso de pesticidas letais (Weindling, 2000b), enquanto essa organização atraiu reformadores dinâmicos que tendiam à esquerda, como Stampar e Pittalluga; no caso latinoamericano os envolvidos eram líderes da saúde pública em seus países de origem. (2006, p.569)

Weindling (2006) evoca o conflito que permeava toda noção de internacionalizar a saúde, qual seja, a omissão calculada em torno das relações de trabalho precárias, que afetavam enormemente a saúde da população. Seus dados mostram que uma das razões para a Organização de Saúde da Liga das Nações chegar ao fim foi justamente quando esta correlação entre relações de trabalho e saúde da população se tornou explícita na fala dos cientistas e tensionou o argumento da educação em saúde, pois pouco adiantava educar a população e não lhe dar condições de vida salubres. Essas conclusões tiveram impacto no futuro da organização. Já a Fundação Rockefeller logrou desempenhar uma performance voltada para a educação em saúde sem dar ênfase às desigualdades sociais, centrada na transferência de tecnologia burocrática e de estratégias de educação sanitária.

Estes autores nos oferecem um panorama complexo do contexto de surgimento da noção de saúde pública e de seu vínculo com estratégias de centralização do poder na esfera federal, das tensões surgidas não apenas entre funcionários da Rockefeller e das elites locais, como também entre as próprias elites locais, como destaca Castro Santos (2004) ao abordar comparativamente o trabalho da Fundação em estados como São Paulo, Rio de Janeiro, Bahia e Pernambuco. Através do foco na situação das disputas, da capacidade de união das facções políticas estaduais, das rivalidades e coesões políticas, percebemos que a "centralização federal das ações em saúde" variou bastante no país. De todo modo, o autor argumenta em favor do aumento do poder central via reforma sanitária, e destaca o papel da educação em saúde como via de construção da autoridade e legitimidade das políticas sanitárias. Mudar o comportamento das pessoas nas periferias e nos interiores se tornou um elemento central no Brasil das primeiras décadas do séc. XX, como 
afirmam Hochman e Armus (2004). Ainda que sob a leitura benevolente de que o Brasil era um imenso hospital porque sua população estava abandonada pelo Estado, o fato importante da associação das campanhas de saúde a campanhas educativas data desse período. O discurso sobre a nação que surge no seio do debate da saúde pública se constitui pelo manejo político das diferenças socioculturais, tomadas como resultado inevitável de uma população adoecida e abandonada. Assim, constrói-se, sob os auspícios de uma positividade projetada sobre o futuro da nação, a eliminação de mosquitos, por um lado, e de hábitos e práticas culturais, por outro - como estratégias complementares.

Cabe perguntar de que forma esta tradição e histórico das políticas de saúde pode nos auxiliar na reflexão sobre processos atuais nos quais a interculturalidade se tornou uma palavra-chave, sendo capaz de mobilizar e dar sentido a cooperações e dinâmicas através das políticas de saúde. Passemos, então, a algumas considerações possíveis sobre como este instigante debate de cunho histórico nos permite refletir sobre a produção de significados em torno da interculturalidade em saúde indígena no Brasil.

Do ponto de vista da produção antropológica recente, as dissertações e teses destacam claramente as numerosas dificuldades do Subsistema de Saúde Indígena em produzir efetivamente um contexto de interculturalidade, conforme citado no início deste texto. A atenção diferenciada, termo de referência no debate brasileiro sobre interculturalidade na saúde indígena (TEIXEIRA, 2017), aponta para questões internas à formação do estado nacional. Se olharmos apenas para o escopo etnográfico, tendemos a projetar que os numerosos problemas da saúde indígena são resultantes de um quadro de preconceito generalizado na relação entre agentes governamentais e povos indígenas. A questão tem amplo fundamento, sendo, por isso, importante entender os manejos específicos do campo da saúde para refletir sobre a correlação entre saúde pública e o discurso da modernização latino-americana. Nesse sentido, a internacionalização da saúde pública (FARIA, 1995; FARIA E COSTA, 2006; FARIA E PAIVA, 2007; WEINDLING, 2006) é um grande advento para pensar o aporte da noção de cultura neste campo, que incluía e ainda inclui políticos, cientistas e educadores.

Considerando este conjunto de reflexões, embora caibam ainda muitas outras possíveis, gostaria de elaborar alguns apontamentos sobre o uso ou, ainda, o uso pouco frequente da noção de interculturalidade na saúde indígena brasileira, fazendo referência fundamental à nossa produção etnográfica recente que aponta importantes deslizes de sentido no manejo do conceito de cultura no interior dos processos assistenciais e burocráticos de produção do que costumamos chamar de atenção diferenciada em saúde indígena. 


\section{Controle social e atenção diferenciada}

Um dos principais debates entre os estudos antropológicos sobre saúde indígena nos anos de 1990, pouco antes do processo dos distritos sanitários ser implantando, dizia respeito ao modelo de atuação da saúde pública para povos indígenas. Além da infraestrutura mínima, havia uma clara preocupação com a construção de uma política pública que considerasse especificidades fundamentais aos povos indígenas como o direito aos seus modos de vida, cultura e território (COSTA, 1987; GALLOIS, 1991; GREENE, 1998, LANGDON, 1991, 1994 e 1996). Podemos notar que a Política Nacional de Atenção à Saúde dos Povos Indígenas de 2002 arregimentou as reivindicações fundamentais das três primeiras conferências nacionais de saúde indígena (1989, 1993 e 2001), dentre elas, a adoção de critérios mais precisos que permitissem a observação de diferenças culturais e que levassem a termo compromissos em torno das demarcações de terras e proteção do patrimônio cultural indígena. Assim, o subsistema de saúde indígena foi erigido em torno do controle social - este, concebido no seio do próprio sistema único de saúde - como pilar não apenas da participação social, mas também da possibilidade de articulação dos saberes indígenas às ações em saúde.

A leitura das etnografias em saúde indígena recentes (FERREIRA 2010, NOVO, 2010, DIAS DA SILVA 2010, ARAÚJO 2012, COLLEVATTI 2012, SANTOS 2013, SCOPEL 2013, DIAS-SCOPEL, 2015) nos revela ações de saúde que continuam a tematizar e refletir tensões do período de formação das propostas que fundamentaram o subsistema de saúde indígena, como, por exemplo, o desenvolvimento e aprimoramento das instâncias de controle social - cuja principal dificuldade enfrentada diz respeito a uma combinação de falta de recursos e de estratégias para articular distintas perspectivas culturais. Assim, um olhar crítico ao estado surge em nossos trabalhos, seja na forma da análise sobre os limites e possibilidades da construção de uma política pública inclusiva, seja na forma de etnografias centradas nas equipes de saúde e que procuram explorar os pontos de vista de profissionais de saúde, assim como dos itinerários burocráticos que se articulam às premissas da atenção diferenciada (DIAS DA SILVA, 2010; ARAÚJO, 2012; GARNELO, 2006; TEIXEIRA, 2012), seja, ainda, na análise de casos que produzem críticas mais gerais ao próprio fazer antropológico e que destacam os domínios de uma antropologia participativa (LANGDON E GARNELO, 2004; SANTOS, 2013).

As questões em torno da esfera do controle social na saúde indígena, apresentados de maneira persistente nos trabalhos citados, sugerem, portanto, tensionamentos e conflitos em torno dos significados atribuídos à ideia de atenção diferenciada. Em certo sentido, tais situações-limite apontadas com frequência nos permitem problematizar o campo governamental - seja pela sua ineficiente e/ou insuficiente infraestrutura (equipamentos), seja pela pouca efetividade na formação de pessoal de saúde capacitado para atuar junto a povos indígenas. 
Permitem-nos, também, abordar a pretendida diferenciação no atendimento a povos indígenas como uma questão central para compreender o uso do conceito de cultura elaborado no interior de processos políticos e consequentes deslocamentos de sentido daí advindos, que tensionam o exercício do olhar antropológico no contexto da saúde indígena. Esse tem sido, inclusive, um traço mais geral das etnografias e artigos publicados no Brasil nos últimos anos, isto é, a percepção de que falta diálogo e de que os agentes governamentais, como os profissionais de saúde, não conseguem entender ou não estão aptos ou interessados em produzir um atendimento diferenciado. Também vemos surgir como questão qualificada para o debate na saúde indígena a ação improvisada dos agentes governamentais diante de atendimentos emergenciais, que dramatizam ao mesmo tempo os conflitos da ordem da infraestrutura e das perspectivas distintas de saúde e doença.

Considerando estas observações, podemos afirmar que a categoria da atenção diferenciada na saúde indígena não pode ser pensada fora das estratégias de aprimoramento do controle social. Esta noção de controle social tem para a saúde indígena, como disse, um duplo valor: tanto se refere à possibilidade do exercício de uma cidadania plena quanto ao de uma identidade étnica igualmente reconhecida pelo estado brasileiro. Assim, as etnografias voltadas para o subsistema de saúde indígena têm se empenhado no sentido de ampliar este debate, contribuindo para apurar estratégias de participação que tem se efetivado nos últimos anos e demonstrado que a estrutura imaginada para o controle social não se traduz em uma rede de atenção diferenciada e nem é capaz de garantir uma reflexão qualificada sobre diferenças culturais e interculturalidade.

A partir de tais contribuições das etnografias recentes, podemos agora elaborar algumas sugestões de reflexão sobre o contexto no qual a interculturalidade adentra a saúde indígena brasileira, em um cenário político nacional pós-constituição de 1988 e após a implantação dos distritos sanitários especiais indígenas no Brasil.

Em primeiro lugar, nota-se certa concorrência da ideia de interculturalidade com a de controle social. Estrito senso, elas seriam estratégias que se complementam, assim como a própria relação entre o Sistema Único de Saúde e o Subsistema de Saúde Indígena. Entretanto, o que se tem verificado é uma sobreposição do controle social, isto é, das dinâmicas da participação social do estado em detrimento de arranjos participativos e entendimentos culturalmente diferenciados. No contexto de uma desigualdade social intensa, o controle social poderia agir como se garantisse ou efetivasse per se a prática de uma atenção diferenciada e, esta, por extensão, de uma zona de interculturalidade. Mas, no cotidiano das ações em saúde, as etnografias apontam justamente para a tensão e o conflito quando o processo de decisão envolvido nos itinerários terapêuticos precisa incluir considerações sobre outros modos culturalmente distintos de entender e lidar com processos saúde-doença.

Em segundo lugar, considerando o processo de construção do aparato estatal da e para a saúde pública, e nos aproveitando da digressão 
realizada em termos das ideias e do tipo de mentalidade política que se constitui ao pensar a saúde como um direito e um bem público, podemos sugerir certo paradoxo a partir do qual nossa saúde pública se desenvolveu, qual seja, a tensão entre centralizar decisões e descentralizar ações em saúde ou, para usar termos mais caros à saúde indígena, a tensão entre atenção diferenciada (centrada na perspectiva dos agentes governamentais e na oferta do serviço, considerando os indígenas como mediadores) e interculturalidade (centrada nas perspectivas indígenas diversas e tendo os agentes governamentais como mediadores). Esta inversão simétrica das posições ocupadas por tais sujeitos históricos tende a projetar a luta política pelo controle social, tornando o debate em torno da interculturalidade menos visível e mais difícil de ser agenciado nas esferas de participação social e mesmo na perspectiva da experiência profissional multidisciplinar prevista na PNASPI.

Em terceiro lugar, é necessário considerar alguns elementos que se assomaram em tempos de pandemia por Covid-19. Segundo dados da recente publicação Pandemia e Território, organizada por Alfredo Wagner de Almeida, Rosa Acevedo e Eriki Melo (2020), a pandemia de Covid-19 entre os povos indígenas brasileiros não ocorre em um vazio sociológico, mas agrava a anterior política de precariedades. No capítulo escrito por Rocha e Loures (2020, p.337-368) sobre o caso do Alto Tapajós, por exemplo, seus efeitos nefastos já são contabilizados com a perda de vários anciãos em curto período de tempo. A situação de agravamento gerado pela pandemia, em um contexto já enfraquecido por uma gestão das precariedades, rompe com a lógica obtusa de uma crise permanente (DIAS DA SILVA, 2021) e expõe seus efeitos nefastos:

A precariedade do sistema de saúde regional causa profunda preocupação. Em Itaituba existem poucos leitos de UTI com respiradores, enquanto Jacareacanga não possui nenhum. (....) Tanto os territórios Munduruku (salvo as Reservas na periferia urbana de Itaituba) quanto o PAE Montanha e Mangabal são de difícil acesso; as comunidades não possuem meios financeiros para arcar com o deslocamento de doentes para as cidades de Itaituba e Jacareacanga. (2020, p.256-257).

Este exemplo aqui escolhido representa muitos outros trabalhados pela coletânea, um sem fim de casos regionais que se descrevem pela precariedade persistente. Pensar as questões atuais da pandemia nos exige recuperar essas permanências anteriores, a violência produzida como crise e que agora se estabelece pela retórica governamental de "mortes inevitáveis".

Por tais razões, é fundamental pensar os processos de adoecimento e cura por dentro dos processos burocráticos e das disputas de sentido em torno dos termos articulação de saberes e atenção diferenciada, produzindo uma associação entre itinerários terapêuticos e itinerários político-administrativos. Sobretudo se considerarmos, conforme sugere a 
publicação organizada por Wagner, Acevedo e Aleixo (2020), que a pandemia de covid-19 não está sendo apenas um fator de agravamento da condição precária da saúde indígena, mas que a mesma, enquanto evento político, enseja ameaças múltiplas e reforça os preconceitos e ataques aos direitos indígenas como um todo. Essa seria uma compreensão de que certas lógicas de articulação da alteridade se repetem em função de dinâmicas de poder específicas e precisam ser pensadas juntas aos itinerários terapêuticos para que sejamos capazes de articular, em nossas perspectivas teórico-metodológicas, ações de cuidado e de governança.

Uma importante atualização das relações entre antropologia e epidemiologia, para relembrar trabalhos pioneiros como os de Menéndez (1998) e Grimberg (1998), seria compreender a noção de interculturalidade em saúde em estreita relação com o manejo político da diversidade cultural que está em jogo, alinhavando distintos cenário de mediação. As formas desenvolvidas para se lidar com a pandemia, como extensão desta problemática, parecem acentuar a artificialidade da distinção entre técnica e política e têm se constituído em uma tecnologia governamental que violenta direitos e ameaça a integridade física e moral dos povos nativos.

\section{Considerações Finais}

Os estudos antropológicos aqui consultados construíram, nos últimos anos, um olhar apurado sobre a política nacional delineada para o atendimento de saúde aos povos indígenas, apontando neste processo uma reflexão consistente sobre uma série de ambiguidades e buscando qualificar histórica e etnograficamente tais deslizes de sentido. Assim, vimos que a noção de atenção diferenciada ocupa um espaço simbolicamente significativo no campo da saúde indígena brasileira, operando sentidos que vão desde a oferta de serviços adaptados às realidades indígenas até se confundir e/ou substituir a própria noção de cultura ou interculturalidade, sendo uma expressão bastante usada na luta por direitos no campo da saúde indígena. Sob os auspícios deste debate, a ideia de interculturalidade vem sendo tecida nos domínios e através das possibilidades vislumbradas por uma larga experiência indigenista pregressa e que teve seu impacto na saúde indígena através, podemos supor, da prevalência de um termo a outro e seus significados indexados ao cotidiano, conforme discutido anteriormente. A importância da conexão deste debate na saúde indígena - seus modos e termos de referenciamento - às políticas indigenistas nos permite refletir sobre aspectos estruturantes de um mesmo processo político:

Sem condições político-morais para um diálogo intercultural, construído desde o local e o regional, baseado num conjunto de princípios e direitos partícipes de um projeto nacional rumo à inclusão e à justiça social, tendo como ponto de partida o 
respeito à diferença de projetos de futuro, não há o que planejar: arriscamo-nos sob as novas vestes da década (sustentabilidade, parceria, participação, capacitação etc.) a repetirmos o pior da tutela e do clientelismo de Estado. (SOUZA LIMA, 2002, p.27)

Esta cautela em torno dos efeitos de nominação faz sentido porque são estes nomes que carregam o poder de renomear experiências anteriores e criar uma noção de tempo linear, quando nos deparamos em nossos trabalhos com círculos viciosos, como tem sido a configuração do poder tutelar em relação aos povos indígenas brasileiros. Imbuída de tal discussão, tornou-se interessante neste texto fazer notar a correlação entre atenção diferenciada e controle social sob os auspícios de uma interculturalidade não nomeada, cujos sentidos vão sendo conferidos através do adjetivo "diferenciado". Longe de uma dimensão de troca e horizontalidades, temos aqui a sugestão de uma diferença nem sempre positivada, como podemos auferir das numerosas anedotas etnográficas que apontam para os preconceitos sofridos pelos povos indígenas na relação com os profissionais de saúde que, de posse das melhores intenções, organizam os termos destas diferenças culturais de modo a reproduzir hierarquias sociais historicamente reconhecidas. Diante de uma crise sanitária, como a pandemia de Covid-19, o desafio continua sendo fazer ver que os direitos indígenas a uma atenção diferenciada na saúde não podem ser justificados por uma ambiguidade de critérios sobre os sentidos atribuídos à diferença, ora positivada, ora negativizada. Assim, embora o controle social seja uma ferramenta indispensável na luta pela aplicação das prerrogativas constitucionais como é o direito à saúde e à cultura e que, inclusive, tem sofrido ataques recentes do governo federal, torna-se, por isso mesmo, fundamental desenvolver uma agenda de pesquisa sobre os caminhos e modos da construção de uma noção de interculturalidade no campo da saúde indígena brasileira, questionando limites e possibilidades das estratégias de participação social construídas através da sugestiva ambiguidade entre os domínios representativos do controle social e da atenção diferenciada. 


\section{Referências nibliográficas}

ALMEIDA, Alfredo Wagner B.; ACEVEDO, Rosa E. M.; MELO, Eriki A (Orgs). Pandemia e Território. São Luís: UEMA Edições/ PNCSA, 2020.

ARAÚJO, R.S. Política Nacional de Atenção à Saúde Indígena no Brasil: dilemas, conflitos e contradições a partir da experiência do Distrito Sanitário Especial do Xingu. Tese (Antropologia Social). Programa de Pós-Graduação em Antropologia social, UFSCAR, São Carlos, 2012.

BRASIL. Ministério da Saúde. Política Nacional de Atenção à Saúde dos Povos Indígenas. 2002, p.42.

CASTRO SANTOS, Luis Antonio. Poder, Ideologias e Saúde no Brasil da Primeira República: ensaio de sociologia histórica. In: HOCHMAN, Gilberto; ARMUS, Diego. Cuidar, curar, controlar. Rio de Janeiro: Fiocruz, 2004, p. 249-294.

COLLEVATTI, Jane Hunger. Dualismo Munduruku: sobre clãs, metades e relações de alteridade em um mundo dividido. 2012. 289f. Tese (Doutorado em Antropologia Social). Programa de Pós-Graduação em Antropologia Social, USP, São Paulo, 2012.

CUETO, Marcos. Tifo, varíola e indigenismo: Manuel Nuñez Butrón e a medicina rural em Puno, Peru. In: HOCHMAN, Gilberto; ARMUS, Diego. Cuidar, curar, controlar. Rio de Janeiro: Fiocruz, 2004, p. 295-330.

DIAS DA SILVA, Cristina. Cotidiano, saúde e política: uma etnografia entre os profissionais da saúde indígena. 2010. 276f. Tese (Doutorado em Antropologia Social) Programa de Pós-Graduação em Antropologia Social, UNB, Brasília, 2010.

DIAS DA SILVA, Cristina. Uma crise permanente: reflexões sobre a política de saúde indígena a partir do caso do Alto Tapajós (PA). Revista Equatorial, v.8, n.1, p. 1-20, jun.,

2021.

DIAS-SCOPEL, Raquel P. A cosmopolítca da gestação, do parto e do pós-parto: práticas de autoatenção e processos de medicalização entre os índios Munduruku. Brasília, Paralelo 15, 2015.

DIEHL, Eliane; LANGDON, Esther J. e DIAS-SCOPEL, Raquel. Contribuição dos agentes indígenas de saúde na atenção diferenciada à saúde dos povos indígenas brasileiros. Cad. Saúde Pública, Rio de Janeiro, v. 28, n. 5, p. 819-831, mai, 2012.

FARIA, Lina. Os primeiros anos da reforma sanitária no Brasil e a atuação da Fundação Rockfeller (1915-1920). Physis - Revista de saúde coletiva, v.5 n. 1, p.109-128, 1995.

FARIA, Lina; COSTA, Maria Conceição. Cooperação Científica Internacional: estilos de Atuação da Fundação Rockefeller e da Fundação Ford. DADOS - Revista de Ciências Sociais, Rio de Janeiro, V. 49, n.1, p. 159 a 191, 2006. 
FARIA. Lina; PAIVA Carlos Henrique A. Saúde e doença na América Latina e no Caribe: perspectivas histórico-sociológicas. Physis - Revista de saúde coletiva, vol. 17, n.1, p. 193-218, 2007.

FERREIRA, Luciana Ouriques. Entre discursos oficiais e vozes indígenas sobre gestação e parto no Alto Juruá: a emergência da medicina tradicional indígena no contexto de uma política pública. 2010. $261 \mathrm{f}$. Tese (doutorado em Antropologia Social) - Programa de Pós-Graduação em Antropologia Social, UFSC, Florianópolis, SC, 2010.

FOLLÉR, Maj-Lis. Intermedicalidade: A zona de contato criada por povos indígenas e profissionais de saúde. In: LANGDON. Esther J. \& GARNELO. Luiza. (Orgs.). Saúde dos povos indígenas. Reflexões sobre antropologia participativa. Rio de Janeiro: contra capa/Brasília: ABA, 2004, p.103-116.

GARNELO, Maria Luiza P. Políticas de Saúde Indígena na Amazônia: Gestão e contradições. In: Elenise Scherer e José Aldemir de Oliveira. (Org.). Amazônia: Políticas Públicas e Diversidade Cultural. 1ed .Rio de Janeiro: Garamond LTDA, 2006, p. $133-160$

GRIMBERG, Mabel. Relações entre epidemiologia e antropologia. ALVES, PC.; RABELO, MC. (orgs.) Antropologia da saúde: traçando identidade e explorando fronteiras [online]. Rio de Janeiro: Editora Fiocruz/Editora Relume-Dumará, 1998, p. 95106.

HOCHMAN, Gilberto e ARMUS, Diego. Cuidar, curar, controlar. Rio de Janeiro: Fiocruz, 2004.

LANGDON, Esther J. Percepção e utilização da medicina ocidental pelos índios Sibundoy e Siona no sul da Colômbia. In: BUCHILLET, Dominique. (org.) Medicinas tradicionais e medicina ocidental na Amazônia. Belém: edições CEJUP, 1991, p. 207228.

LANGDON, Esther J. Representações de Doença e Itinerário Terapêutico dos Siona da Amazônia Colombiana. In: SANTOS, Ricardo V. \& COIMBRA JR., Carlos E. A. (orgs.). Saúde e povos indígenas. Rio de Janeiro: Fiocruz, 1994, p. 115-142.

LANGDON, Esther J. A doença como experiência: a construção da doença e seu desafio para a prática médica. Antropologia em primeira mão, Vol. 12, p. 1-24, 1996.

LANGDON, Esther J.; DIEHL, Eliane. Participação e autonomia nos espaços interculturais de saúde indígena: reflexões a partir do Sul do Brasil. Saúde e Sociedade, Vol. 16, n.2, p. 16-36, 2007.

LÖWI, Ilana. Representação e intervenção em saúde pública: vírus, mosquitos e especialistas da Fundação Rockefeller no Brasil. Hist. cienc. saude-Manguinhos, v.5, n.3, Fev, p. 647677, 1999.

MENÉNDEZ, Eduardo. Antropologia medica e epidemiologia: processo de convergência ou processo de medicalização? ALVES, PC.; RABELO, MC. (orgs.) Antropologia da 
Espaço Ameríndio

saúde: traçando identidade e explorando fronteiras [online]. Rio de Janeiro: Editora Fiocruz/Editora Relume-Dumará, 1998, p. 71-93.

NOGUERA, Carlos. Luta antialcoólica e higiene social na Colômbia, 1886-1948. In: HOCHMAN, Gilberto; ARMUS, Diego. Cuidar, curar, controlar. Rio de Janeiro: Fiocruz, 2004, p.99-124.

NOVO, M. P. 2010. Os Agentes Indígenas de Saúde do Alto Xingu. Brasília: ABA/Paralelo 15, 158pp.

PALMER, S. 2015. A gênese da saúde global: a Fundação Rockefeller no Caribe e na América Latina. Rio de Janeiro, Editora Fiocruz, 421pp.

PONTES, Ana Lúcia; REGO, Sérgio e GARNELO, Luiza. O modelo de atenção diferenciada nos Distritos Sanitários Especiais Indígenas: reflexões a partir do Alto Rio Negro/AM, Brasil. Ciência \& Saúde Coletiva, vol. 20, n. 10, p. 3199-3210, 2015.

ROCHA, Bruna C.; LOURES, Rosamaria S. P. A expropriação territorial e o Covid-19 no alto Tapajós, PA. In: ALMEIDA, Alfredo Wagner B.; ACEVEDO, Rosa E. M.; MELO, Eriki A (Orgs). Pandemia e Território. São Luís: UEMA Edições/ PNCSA, 2020, p. 337-368.

SANTOS, L. Controvérsias em torno das práticas e terapias de cura: a epidemia de cóleramorbus em Pernambuco (1855). 281p. Tese de Doutorado (Antropologia Social). Programa de Pós-Graduação em Antropologia Social, USP, São Paulo, 2013.

SCOPEL, Daniel. Uma etnografia sobre a pluralidade de modelos de atenção à saúde entre os índios Munduruku na terra indígena Kwatá Laranjal, Borba, Amazonas: práticas de automação, xamanismo e biomedicina. 262f. Tese de Doutorado (Antropologia Social). Programa de Pós-Graduação em Antropologia Social, UFSC, Florianópolis, 2013.

SOUZA LIMA, Antonio Carlos; CARVALHO, Luis Felipe S. Interculturalidade(s):das retóricas às práticas. Uma apresentação. In: SOUZA LIMA, Antonio C.; CARVALHO, Luis F. S.; RIBEIRO, Gustavo L. (Orgs.). Interculturalidade(s): entre ideias, retóricas e práticas em cinco países da América Latina. Rio de Janeiro: Associação Brasileira de Antropologia; Contra Capa, 2018.

SOUZA LIMA, A. C. 2002. Diversidade cultural e política indigenista no Brasil. In Revista Tellus, v. 2, n. 3, p. 11-31, 2002.

TEIXEIRA, C. C. A produção política da repulsa e os manejos da diversidade na saúde indígena brasileira. Revista de Antropologia, São Paulo, USP, 2012, V. 55 Nº 2.

TEIXEIRA, C.C. Participação social na saúde indígena: a aposta contra a assimetria no Brasil? Revista Amazônica 9(2):1-18, 2017.

TEIXEIRA, C. C. \& SILVA, C. D. 2019. Indigenous health in Brazil: reflections on forms of violence. Vibrant. Virtual brazilian Anthropology. Vol. 16, pp. 1-22. 
Espaço Ameríndio

WEINDLING, Paul. As origens da participação da América Latina na Organização de Saúde da Liga das Nações, 1920 a 1940. História, Ciências, Saúde - Manguinhos, v. 13, n. 3, 2006, p. 555-570.

Recebido em: 20/07/2021* Aprovado em: 09/08/2021 * Publicado em: 30/08/2021 